\title{
Bacterial exposure leads to variable mortality but not a measurable increase in surface antimicrobials across ant species
}

\author{
Omar Halawani ${ }^{\text {Corresp., } 1}{ }^{1}$, Robert R Dunn ${ }^{1}$, Amy M Grunden ${ }^{2}$, Adrian A Smith ${ }^{\text {Corresp. } 3,4}$ \\ ${ }^{1}$ Department of Applied Ecology, North Carolina State University, Raleigh, North Carolina, United States \\ 2 Department of Plant and Microbial Biology, North Carolina State University, Raleigh, North Carolina, United States \\ 3 Department of Biological Sciences, North Carolina State University, Raleigh, North Carolina, United States \\ 4 Research \& Collections, North Carolina Museum of Natural Sciences, Raleigh, North Carolina, United States \\ Corresponding Authors: Omar Halawani, Adrian A Smith \\ Email address: ohalawa@ncsu.edu, aasmith7@ncsu.edu
}

Social insects have co-existed with microbial species for millions of years and have evolved a diversity of collective defenses, including the use of antimicrobials. While many studies have revealed strategies that ants use against microbial entomopathogens, and several have shown ant-produced compounds inhibit environmental bacterial growth, few studies have tested whether exposure to environmental bacteria represents a health threat to ants. We compare four ant species' responses to exposure to Escherichia coli and Staphylococcus epidermidis bacteria in order to broaden our understanding of microbial health-threats to ants and their ability to defend against them. In a first experiment, we measure worker mortality of Solenopsis invicta, Brachymyrmex chinensis, Aphaenogaster rudis, and Dorymyrmex bureni in response to exposure to $E$. coli and $S$. epidermidis. We found that exposure to $E$. coli was lethal for $S$. invicta and $D$. bureni, while all other effects of exposure were not different from experimental controls. In a second experiment, we compared the antimicrobial ability of surface extracts from bacteria-exposed and nonexposed S. invicta and B. chinensis worker ants, to see if exposure to E. coli or S. epidermidis led to an increase in antimicrobial compounds. We found no difference in the inhibitory effects from either treatment group in either species. Our results demonstrate the susceptibility to bacteria is varied across ant species. This variation may correlate with an ant species' use of surface antimicrobials, as we found significant mortality effects in species which also were producing antimicrobials. Further exploration of a wide range of both bacteria and ant species is likely to reveal unique and nuanced antimicrobial strategies and deepen our understanding of how ant societies respond to microbial health threats. 
1 Bacterial exposure leads to variable mortality but not

2 a measurable increase in surface antimicrobials

3 across ant species

4

5 Omar Halawani ${ }^{1}$, Robert R. Dunn ${ }^{1}$, Amy M. Grunden ${ }^{2}$, Adrian A. Smith ${ }^{3,4}$

6

$7 \quad{ }^{1}$ Applied Ecology, North Carolina State University, Raleigh, NC, USA

$8 \quad 2$ Plant and Microbial Biology, North Carolina State University, Raleigh, NC, USA

$9 \quad{ }^{3}$ Biological Sciences, North Carolina State University, Raleigh, NC, USA

$10 \quad{ }^{4}$ Research \& Collections, North Carolina Museum of Natural Sciences, Raleigh, NC, USA

11 Corresponding Authors:

12 Omar Halawani ${ }^{1}$

13 Adrian A. Smith ${ }^{3,4}$

1411 W Jones St, Raleigh, NC, 27601, USA

15 Email address: oghalawani@gmail.com, aasmith7@ncsu.edu 
16

17

\section{Abstract}

7

8

evolved a diversity of collective defenses, including the use of antimicrobials. While many studies have revealed strategies that ants use against microbial entomopathogens, and several have shown ant-produced compounds inhibit environmental bacterial growth, few studies have tested whether exposure to environmental bacteria represents a health threat to ants. We compare four ant species' responses to exposure to Escherichia coli and Staphylococcus epidermidis bacteria in order to broaden our understanding of microbial health-threats to ants and their ability to defend against them. In a first experiment, we measure worker mortality of Solenopsis invicta, Brachymyrmex chinensis, Aphaenogaster rudis, and Dorymyrmex bureni in response to exposure to $E$. coli and $S$. epidermidis. We found that exposure to E. coli was lethal for $S$. invicta and D. bureni, while all other effects of exposure were not different from experimental controls. In a second experiment, we compared the antimicrobial ability of surface extracts from bacteriaexposed and non-exposed S. invicta and B. chinensis worker ants, to see if exposure to E. coli or S. epidermidis led to an increase in antimicrobial compounds. We found no difference in the inhibitory effects from either treatment group in either species. Our results demonstrate the susceptibility to bacteria is varied across ant species. This variation may correlate with an ant species' use of surface antimicrobials, as we found significant mortality effects in species which also were producing antimicrobials. Further exploration of a wide range of both bacteria and ant species is likely to reveal unique and nuanced antimicrobial strategies and deepen our understanding of how ant societies respond to microbial health threats. 
38

39

40

41

42

43

44

45

46

47

48

49

50

51

52

53

54

55

56

57

58

59

\section{Introduction}

Organisms that live in societies, whether they are ants, termites or humans, benefit from cooperative defense, offspring care, and foraging success. However, high levels of relatedness in some social species, combined with high densities of individuals, whether in big ant colonies or big human cities, can cause greater susceptibility to pathogens and parasites (Hughes, Eilenberg \& Boomsma, 2002; Sengupta, Chattopadhyay \& Grossart, 2013; Schmid-Hempel, 1998). Human societies reduce pathogenic and parasitic loads in many ways, in particular, antibiotics have saved millions of lives (Levy, 1992). Like humans, ants also have hygienic behaviors that reduce transmission (Konrad et al., 2018), can employ vaccination-like behavior (Konrad et al., 2012), and employ a variety of antimicrobials (Schlüns \& Crozier, 2009). For social insects in general, and ants in particular, a first step in understanding antimicrobial strategies is to assess which microbes present health threats and how responses to microbial exposure might vary.

Extant social insect taxa have co-existed with microbial species for millions of years and have evolved a diversity of collective defenses (Meunier, 2015). These defenses include hygienic behaviors such as allogrooming — the grooming of nest-mates — or the removal of waste and dead individuals (Cremer, Armitage \& Schmid-Hempel, 2007). Ants and other social insects also produce prophylactic antimicrobial compounds (Traniello, Rosengaus \& Savoie, 2002; Yek \& Mueller, 2011). In ants, prophylactic antimicrobial compounds are most well-documented in response to fungal entomopathogens (Schlüns \& Crozier, 2009). However, the microbial-rich environments of ground-nesting ants facilitates interactions with many more species of bacteria than fungi, and many of these bacteria seem likely to have the potential to kill ants, even if they are not specialized entomopathogens (Hoggard et al., 2013). 
How harmful exposure to non-entomopathogenic bacteria is to ants is largely unknown.

61 However, many studies have demonstrated that compounds produced by ants are effective at

62 inhibiting growth of non-entomopathogens. For example, one early study showed inhibition of

63 the gram-negative bacterium E. coli (Mackintosh et al., 1995) by peptides synthesized by the

64 metapleural glands of the ant Myrmecia gulosa (Fabricius, 1775). Concentrations of metplueral

65 gland secretions of at 10 -ant equivalents had a $99 \%$ kill rate on microbial cells. Metaplueral

66 gland peptides can disrupt the cell walls of gram-negative bacteria (E. coli) as well as plasma

67 membranes of gram-positive bacteria (Bacillus cereus) (Mackintosh et al., 1995). The venom

68 from Solenopsis invicta (Buren, 1972) contains multiple alkaloids that have different levels of

69 antimicrobial effectiveness against gram-negative and gram-positive bacteria (Blum et al., 1958),

70 with a generally higher ability to inhibit gram-positive bacteria (Jouvenaz, Blum \& MacConnell,

71 1972). In another study, S. invicta venom alkaloids were isolated and found to be effective at

72 inhibiting Pseudomonas fluorescens biofilms (Carvalho et al., 2019). Finally, a comparison of

73 surface extracts from 20 ant species from four subfamilies found that extracts from $40 \%$ of tested

74 species were ineffective at inhibiting the growth of Staphylococcus epidermidis at just a 5-ant

75 extract equivalent (Penick et al., 2018). That comparative study as well as others on wasps

76 (Hoggard et al., 2011; 2013), bees (Stow et al., 2007), and thrips (Turnbull et al., 2010) draw

77 evolutionary conclusions about these organisms' antimicrobial activity by assessing their ability

78 to inhibit a non-entomopathogenic bacterial species (usually Staphylococcus spp.). However,

79 although ant-produced compounds are capable of inhibiting these bacteria, we do not know

80 whether exposure to non-entomopathogenic and unfamiliar bacteria represent an actual health

81 threat that ants would benefit from being able to defend against. 
83 challenges of pathogens upregulate individual and group immunity. In a study with the ant

84 Formica exsecta Nylander, 1846, workers were orally exposed to Serratia marcescens, E. coli,

85 or Pseudomonas entomophila (Stucki et al., 2019). Antimicrobial gene expression of ants

86 exposed to $P$. entomophila and E. coli was upregulated after exposure, possibly as a general

87 immune response from exposure to a high bacterial load or as the ant's prophylactic response.

88 The response of $F$. exsecta suggested that even non-entomopathogenic bacteria (E. coli) can

89 provoke immune or antimicrobial responses from ants. However, extrapolation of results from a

90 few species of ants to general patterns are likely to mislead, as ants are a diverse group of

91 organisms with variable life history traits that likely result in different strategies for dealing with

92 microbial exposure. Comparative studies across ant species are likely to reveal key differences in 93 antimicrobial strategies.

Recently, the lethality of fungal pathogen exposure was compared across 12 species of ants from 4 genera (Bos et al., 2019). The study found species-level mortality differed across, and even within, ant genera in response to identical pathogen exposure. In addition to this, the

97 three mostly closely related species tested had the most similar responses, suggesting disease resistance might be phylogenetically linked traits. Similar conclusions were reached in a study of surface antimicrobials collected from 20 species of ants (Penick et al., 2018). The antimicrobial ability, measured through inhibition of $S$. epidermidis cultures, using ant-derived surface extracts was highly variable across species; however, there was a phylogenetic signal associated with

102 species that yielded inhibitory extracts. In this study, we consider four ant species (Solenopsis invicta, Brachyponera chinensis

104 (Emery, 1895), Aphaenogaster rudis Enzmann, 1947, and Dorymyrmex bureni (Trager, 1988)) 
105 whose surface antimicrobials have been shown to be differently effective at inhibiting the

106 human-associated bacteria species, Staphylococcus epidermidis (Penick et al., 2018). In Penick

107 et al. (2018), surface extracts from $S$. invicta and D. bureni workers were very effective at

108 inhibiting growth of $S$. epidermidis, whereas $A$. rudis and B. chinensis ants showed weak

109 inhibitory ability. These results and the above referenced pharmacological work indicating that

110 some ant-derived compounds effectively inhibit the growth of $S$. epidermidis and E. coli bacteria

111 have led us to the research question of whether non-ant associated bacteria represent an actual

112 health threat to different ant species. Perhaps ants which are susceptible to exposure to a broad

113 range of bacteria produce broadly effective antimicrobials as a compensatory strategy. Therefore,

114 we first compare the lethality of bacterial exposure across those four ant species to a gram-

115 positive bacterium, $S$. epidermidis, and a gram-negative bacterium, E. coli. We do this by

116 exposing live groups of ant workers with agar-grown bacteria and measuring their mortality over

11748 hours.

118 In a second experiment, we tested if exposure to bacteria under these conditions resulted

119 in an increase in antimicrobial compounds on the bodies of two of these species $(S$. invicta and

120 B. chinensis). In a previous study, surface extracts from $S$. invicta were strong inhibitors of

121 bacterial growth, and B. chinensis lacked inhibitory ability (Penick et al., 2018). One possible

122 explanation for this difference is that some species may deploy antimicrobial compounds only in

123 response to exposure to harmful microbes. We test this by extracting surface compounds from

124 two species of bacteria-exposed ants and testing their bacterial inhibitory ability as compared to a

125 control. We predicted that exposure to a potentially lethal bacterial challenge would result in an

126 increase of antimicrobial ability from ant surface extracts, which would indicate that the 
127 antimicrobial abilities of some ants are able to be conditionally deployed to meet direct microbial 128 challenges.

129

130

\section{Materials \& Methods}

Bacteria were sourced from Carolina Biological Supply Company. Staphylococcus

epidermidis and Escherichia coli strain K12 were kept in glycerol stocks at $-80{ }^{\circ} \mathrm{C}$, then spread

onto BD Difco ${ }^{\mathrm{TM}} \mathrm{LB}$, Miller (Fisher Scientific) agar $100 \mathrm{~mm}$ x $15 \mathrm{~mm}$ petri dish plates. Plates were incubated for $24 \mathrm{~h}$ at $35^{\circ} \mathrm{C}$. Bacteria were cultured on plates for experiment 1 at 0.5

MacFarland standard. For experiment 2, bacteria from agar plates were also cultured in liquid

BD Difco ${ }^{\mathrm{TM}} \mathrm{LB}$, Miller media. Liquid cultures were incubated for $24 \mathrm{~h}$ at $35^{\circ} \mathrm{C}$ before being used in assays.

\section{Experiment 1: Ant mortality in response to exposure to bacteria}

Worker mortality in response to bacterial exposure was measured across four ant species.

140 Fire ants, Solenopsis invicta, were collected between June-December of 2018 in Raleigh, NC,

141 USA by collecting the tops of mounds with a shovel. Aphaenogaster rudis group ants were

142 collected in Durham, NC, USA and Raleigh, NC from July to August of 2018 by aspirating

143 workers from within their nests. Asian needle ants, Brachyponera chinensis, were collected in

144 Raleigh, NC in December 2018 to May 2019 by opening dead logs to expose workers for

145 collection via aspiration. Dorymyrmex bureni colonies were collected in Hoffman, NC, USA in

146 June 2019 by collecting mounds with a shovel. Species used in this and the following experiment

147 were identified using morphological keys (MacGown, 2014), and voucher specimens are in the

148 collection of author AAS at the North Carolina Museum of Natural Sciences. Each species of

149 ants was separated from its nesting material to reduce further environmental (microbial) 
150 interaction and kept in the lab for $<24 \mathrm{~h}$ before experimentation. Before experimentation, while

151 in the lab, ants were given a supply of $20 \%$ sugar water (Kay et al., 2014).

152 In each exposure treatment, we used 200 S. invicta workers and 50 B. chinensis, D.

153 bureni, and A. rudis workers (Fig. S1). The difference in number of workers used for S. invicta

154 was based on what could be consistently captured from colonies. Experiments with each species

155 were replicated across 15 colonies, where each colony was subject to three treatments.

156 Treatments were: exposure to E. coli, exposure to S. epidermidis, or exposure to sterile agar as

157 control. Exposure experiments were performed in lid-covered deep petri dishes (100mm x 25

$158 \mathrm{~mm}$ ). The dishes were prepared with Insect-A-Slip (BioQuip Products) applied around the

159 interior edge to prevent ant escape. Ants were exposed to a small piece of agar $\left(10 \mathrm{~mm} \mathrm{x} 9.7 \mathrm{~cm}^{2}\right)$

160 that had a bacterial lawn of S. epidermidis, E. coli, or no bacterial growth as a control. Bacterial

161 lawns were grown from liquid culture incubated overnight at $35^{\circ} \mathrm{C}$ in a shaking incubator

162 adjusted to a 0.5 MacFarland standard. In the experimental arena, agar pieces with and without

163 bacteria were hydrated with $100 \mu \mathrm{l}$ of MilliQ $\mathrm{H}_{2} \mathrm{O}$, this prevented agar from drying out and

164 encouraged ant interaction with agar. Depending on the species being tested, all 200 or 50 ant

165 workers were introduced at once to the experimental arena after water was absorbed by agar by

166 directly placing ants on agar to ensure at least one point of direct exposure. Mortality was

167 measured by counting dead ants at 24 and $48 \mathrm{~h}$. Observations were recorded when ants tunneled

168 into agar, as an additional indication of direct interaction with the bacteria.

169 We tested the mortality effect of exposing a group of workers as compared to workers

170 from the same colony exposed to control, non-bacterial, treatments. Data at $24 \mathrm{~h}$ and $48 \mathrm{~h}$ were

171 graphed and analyzed with a Friedman's rank sum test with Finner post hoc pairwise

172 comparison. Friedman's test is similar to a one-way ANOVA for an unreplicated complete 
173 blocked design of nonparametric data (García et al., 2010). The Finner post hoc comparison

174 procedure was used for indicating significance of treatment effects. Finner's post hoc uses a step-

175 down p-value adjustment value; it rejects test statistics when $\mathrm{p}_{\mathrm{i}}>1-(1-\mathrm{a})^{(\mathrm{k}-1) / \mathrm{I}}$ (García et al.,

176 2010). Friedman's statistical tests used at a significance level of $\alpha=0.05$, and Finner post hoc

177 used an adjusted threshold level of significance of $\alpha_{1}=0.0975, \alpha_{2}=0.05$, or $a_{3}=0.0336$.

178 Analysis was carried out in R version 3.5.2 (R Core Team, 2017) using the packages scmamp

179 (Calvo \& Santafe, 2016) and devtools (R Core Team, 2017).

\section{Experiment 2: Does exposure to bacteria lead to an increased presence of surface}

181 antimicrobials?

182

We compared the antimicrobial ability of surface extracts from bacteria-exposed and non-

exposed S. invicta and B. chinensis worker ants. We wanted to know if antimicrobial activity of

184

surface extracts was a constant feature of these species, or something that might be responsive

and increasing when exposed to bacterial threats. For the experiment, we collected B. chinensis

186

ants by opening wood logs with their nests and aspirating workers. The ants were collected

between January and May 2019. To collect $S$. invicta ants, the tops of nest mounds were

removed, and workers were aspirated from removed soil. Ants were collected between June and

December 2018. Both species were collected in Raleigh, NC.

The experiment consisted of an exposure treatment followed by extracting surface

As was done for experiment 1,200 S. invicta workers and 50 B. chinensis workers were used for

each exposure treatment. We used 15 colonies per species for treatments, in an incomplete block 
196 bacterial cultures of E. coli and S. epidermidis adjusted to a 0.5 MacFarland standard after 197 growing overnight at $35^{\circ} \mathrm{C}$ in a shaking incubator. $100 \mu \mathrm{l}$ of MilliQ $\mathrm{H} 2 \mathrm{O}$ was pipetted under the 198 agar piece to hydrate the media and encourage ants to interact with the agar plugs. Exposure 199 treatments ran for $6 \mathrm{~h}$. Then, any dead individuals were removed from exposure before freeze200 killing the remaining living workers for extraction. The $6 \mathrm{~h}$ exposure time was determined from 201 earlier trials and selected as a, largely, sub-lethal level of exposure as lethal effect of exposure 202 were first seen after $6 \mathrm{~h}$.

Surface compounds of 40 workers from each exposure treatment were extracted in $360 \mu \mathrm{l}$ 204 isopropanol for $15 \mathrm{~min}$ after an initial vortex spin for $15 \mathrm{~s}$. Whole workers were used, and ant 205 bodies remained in-tact through the vortexing and solvent extraction. Previous studies have shown effectiveness of using polar solvents (e.g. ethanol) to extract antimicrobial compounds 207 (Penick et al., 2018; Stow et al., 2007; Turnbull et al., 2011). Extracts were filtered through 0.2 micron SEP filters (Stow et al., 2007). Isopropanol extracts were evaporated in a vacuum 209 centrifuge then resuspended in $360 \mu \mathrm{LB}$ media. We adjusted a 96 well plate assay protocol for testing antimicrobial ability against 211 bacterial liquid culture (Stow et al., 2007). The initial 40-worker-ant extract was divided into 4 212 equal parts; 10 ant equivalents of ant body-surface extracts (90 $\mu$ l) were tested against 100 213 CFU's of either S. epidermidis or E. coli. Bacterial controls of 100 CFU's bacteria ( $S$. 214 epidermidis or E. coli) with LB media were plated as maximum growth controls. Another 10 ant 215 equivalent extracts suspended in LB media were plated as minimum growth controls. Media 216 controls were also plated to verify there was no contamination. Plates were incubated at $35{ }^{\circ} \mathrm{C}$ 217 for $18 \mathrm{~h}$ before pipetting $10 \mu \mathrm{l}$ of WST-8 (PromoKine, Heidelberg, Germany) followed by 218 another hour of incubation to allow the salt to bind to available live cells. WST-8 salt binds to 
219 cellular membranes of organisms that are undergoing active transport, and therefore, provides a

220 colorimetric method to analyze live microbial count in culture (Braun et al., 2018). After

221 incubation, optical density was measured at $\mathrm{OD}_{600}$ with $5 \mathrm{~s}$ shaking before reading using a plate

222 reader (SpectraMax M5, Molecular Devices, USA).

223

$\mathrm{OD}_{600}$ readings of the well plate were comparable values across the plate because of

224 WST-8 binding equally to available live cells (PromoKine, Heidelberg, Germany). Readings of

exposure treatment workers were measured as percent inhibition adjusted relative to the control

226

227

228

229

230

231

232

233

234

235

236

237

238

239

240

241

treatment workers. Antimicrobial ability was determined by comparing adjusted percent

inhibition to plated maximum and minimum growth controls. Final results were reported as

change in percentage of inhibition of microbes between treatment and control groups. Results

provided either a positive or negative inhibition value based on the treatment inhibition relative

to the control.

In our results some of the outlying data points are percent inhibition measures beyond $100 \%$ and below $0 \%$. Each data point is a measure of inhibition in wells where half of the ant extract is added to an experimental well with live bacteria; however, we report this measure relative to two other wells: one containing only bacteria and media (a maximum bacterial growth control) and the second containing only media and the other half of the ant extract (a minimum growth control). For the outlying points beyond $100 \%$, the half of the ant extract used as minimum growth control had a higher absorbency reading (the proxy for bacterial growth) than the other half of the ant extract used in the experimental well. Minimum growth control wells could have higher absorbency readings from WST-8 binding to available molecules present in the extract, such as carbohydrates or even secondary products that could be contributing to the antimicrobial ability seen in the experimental well. For the outlying points below $0 \%$, the 
242 experimental well absorbency was higher than the maximum growth control. This was likely due

243 to the ant extract failing to inhibit the microbial challenge in the experimental well, and instead

244 supplementing the growth of the bacteria culture.

245 We tested if antimicrobial ability showed a conditional response with a Kruskal Wallis

246 rank sum test. The Kruskal Wallis analysis tests non-parametric data for multiple groups when

247 assumptions for ANOVA are not met - in our case, our data was not a complete design. Some

248 replicates were comprised of samples from two nests to complete all three treatments. In these

249 instances, a control and single treatment group were sampled from colonies twice—once for $E$.

250 coli and once for S. epidermidis. All statistical tests used a threshold level of significance of $\alpha=$

251 0.05. Analysis was carried out in R version 3.5.2 (R Core Team, 2017) using the packages dplyr

252 (Wickham et al., 2018) and devtools (R Core Team, 2017).

253 Results

254

255

256

257

258

259

260

261

262

263

264

\section{Experiment 1: Ant mortality in response to exposure to non-entomopathogenic bacteria}

The effects of exposure for all ants to S. epidermidis and E. coli after 24 and at $48 \mathrm{~h}$ are

shown in Figure 1. In control groups across our experiment, mortality was low with average proportions of 0.027 at $24 \mathrm{~h}$ and 0.064 at $48 \mathrm{~h}$. In addition, across all treatments and all species

tested, agar discs had visible evidence of excavation upon first inspection when the $24 \mathrm{~h}$ mortality count was made.

Solenopsis invicta showed significant mortality to exposure (Table 1; Figure 1). At 24 h, there was significant mortality from $S$. epidermidis and E. coli (Friedman's ANOVA F(2) = 8.93, $\mathrm{p}=0.011$; post-hoc analyses Finner $\mathrm{p}<0.01$, Cohen's $d$ effect sizes $\geq 0.68$ ). At $48 \mathrm{~h}$, there was only significance from exposure to $E$. coli (Friedman's ANOVA $48 \mathrm{~h} \mathrm{~F}(2)=16.3, \mathrm{p}=0.022$;

post-hoc analyses Finner $\mathrm{p}=0.003$, Cohen's $d$ effect size 0.8 ). Dorymyrmex bureni also 
265 displayed significant mortality to E. coli exposure at $24 \mathrm{~h}$ (Friedman's ANOVA $24 \mathrm{~h} \mathrm{~F}(2)=23.3$,

$266 \mathrm{p}<0.0001$; Finner $\mathrm{p}<0.001$, Cohen's $d$ effect size 1.27) and $48 \mathrm{~h}$ (Friedman's ANOVA $48 \mathrm{~h}$

$267 \mathrm{~F}(2)=19.7, \mathrm{p}<0.0001$; Finner $\mathrm{p}<0.001$, Cohen's $d$ effect size 5.74; Figure 1). A significant

268 treatment effect was detected for $A$. rudis at both 24 and $48 \mathrm{~h}$, but in post-hoc comparison the

269 only significant difference between groups was comparing mortality bacterial treatments at $48 \mathrm{~h}$

270 (Friedman's ANOVA $48 \mathrm{~h} \mathrm{~F}(2)=10.3, \mathrm{p}<0.01$; Finner $\mathrm{p}=0.01$, Cohen's $d$ effect size 1.11 ).

271 All other comparisons were not significant, and mortality from both bacterial treatments was not

272 different from the control. Brachyponera chinensis showed no significant mortality to either

273 treatment (Table 1).

274 Experiment 2: Does exposure to bacteria lead to an increased presence of surface

275 antimicrobials?

276 Exposure seemed to have no effect on surface antimicrobial ability for both S. invicta and 277 B. chinensis. Antimicrobial ability was calculated from $\mathrm{OD}_{600}$ readings after WST-8 was added 278 to wells and plates were incubated for one hour. Figure 2 shows $S$. invicta has similar 279 antimicrobial ability to inhibit E. coli (Figure 2a) or S. epidermidis (Figure 2b) with and without 280 treatment exposures, $E$. coli $(\mathrm{KW}$ chi-squared $=0.36, \mathrm{df}=1, \mathrm{p}=0.55$, epsilon square effect size $2810.01)$, S. epidermidis (KW chi-squared $=1.3011, \mathrm{df}=1, \mathrm{p}=0.254$, epsilon square effect size $2820.045)$. Figure 3a shows $B$. chinensis lacks ability to completely inhibit E. coli but has 283 antimicrobial ability to inhibit S. epidermidis (Figure 3b). Exposure to bacteria did not lead to 284 significant changes in antimicrobial ability $($ S. epidermidis $\mathrm{KW}$ chi-squared $=0.01, \mathrm{df}=1, \mathrm{p}=$ 2850.92 , epsilon square effect size $0 ; E$. coli $\mathrm{KW}$ chi-squared $=2.42, \mathrm{df}=1, \mathrm{p}=0.12$, epsilon square 286 effect size 0.08). 


\section{Discussion}

289 Our first experiment demonstrated that exposure to a common bacterium-E. coli-could kill 290 two of the four ant species we tested, S. invicta and D. bureni-two species that displayed strong 291 antimicrobial ability (Penick et al., 2018). Exposure to S. epidermidis had no significant effect on 292 any of the tested ants except for S. invicta workers at $24 \mathrm{~h}$ of exposure. The other two ants we 293 tested, B. chinensis and A. rudis group, did not previously demonstrate antimicrobial ability nor 294 did they die from exposure to either bacterium used in this study. Our finding indicates that, like 295 antimicrobial ability, susceptibility to bacterial exposure varies across species. Additionally, our results could be an indication of a linkage between an ant species' susceptibility to bacterial exposure and antimicrobial ability. However, this requires further testing and considerations that

298

299

300 301 302 303 304 305 306 307 308 309 our experiments did not account for, as will be discussed below.

In our second experiment, S. invicta and B. chinensis were subjected to a sub-lethal period of bacterial exposure followed by an antimicrobial assay of their surface extracts. We aimed to test for a possible increase in antimicrobial ability in response to exposure to the focal bacteria species. We predicted that exposure to a bacterial challenge would result in an increase of antimicrobial ability from ant surface extracts, which would indicate that surface antimicrobials of some ants are able to be conditionally deployed to meet direct microbial challenges. As tested, we found no evidence of a change in antimicrobial ability akin to any response to bacterial exposure. Fire ant, $S$. invicta, extracts demonstrated near-complete inhibitory ability, as was previously found (Penick et al., 2018), against S. epidermidis independent of previous exposure to the bacteria species. In addition, E.coli growth was inhibited by the surface extracts of fire ants. Surface extracts from $B$. chinensis also inhibited growth of $S$. epidermidis. This differs from the result of Penick et al. (2018) which found no effect of surface 
311 extracts of $B$. chinensis on $S$. epidermidis. Our study used isopropanol as a solvent for extraction.

312 In contrast, Penick et al. (2018) used ethanol. Surface antimicrobials on B. chinensis may be non-

313 polar antimicrobial compounds that ethanol could not extract.

314 Our experiments focused on how ants respond to exposure to bacterial species that are not

315 known to have an evolved relationship with the ants. Our aim was to broaden our understanding

316 of how microbes might be influencing antimicrobial traits of ants. Many studies of bacteria in

317 ants focus on bacterial species that have specific, and often co-evolutionary, associations with

318 insects. For instance, intracellular bacteria that have evolved to be largely maternally transmitted.

319 Wolbachia species are commonly associated with insects, including ants (Ramalho, Bueno \&

320 Moreau, 2017). The bacteria likely target reproductive function but do not seem to kill infected

321 adult ants (Wenseleers et al., 1998; Kautz, Rubin \& Moreau, 2013). Species of the genus

322 Spiroplasma were found in many of the 95 ant genera considered in a recent study (Kautz, Rubin

323 \& Moreau 2013). Spiroplasma species can be pathogens of both vertebrates and plants; Kautz,

324 Rubin \& Moreau (2013) hypothesize that they might also negatively affect ants, but to date this

325 hypothesis remains untested. In another study a Pseudomonas species was found by Lofgren and

326 colleagues (1975) on dead ant bodies. The authors suggested that this species might have killed

327 the ants. The health effects that internal and environmental bacteria have on ants are only

328 beginning to be explored.

Our experiments involved exposure to extremely high concentrations of bacteria (full "lawns" of bacterial growth on agar). These high concentrations are likely beyond what ants

331 normally encounter. In our experiments bacterial exposure was lethal for antimicrobial producing 332 ants, however under more natural concentrations the antimicrobial tactics the ants use might save 333 them from the mortality effects seen in our experiments. Secondly, our experiments isolated 
334 workers outside of their normal nesting environments. These non-natural situations were used in

335 this first experiment as a means of assuring the ants interacted with and were exposed to the

336 bacteria. However, nesting environment and behavioral responses such as isolation and

337 avoidance of bacterial-rich areas could be integral antibacterial strategies that ants use, which

338 were not available to them in our study. Certainly, the microbiomes that ants maintain in their

339 natural nests are known to be distinct from the surrounding environment and low in number

340 potential bacterial and fungal pathogens (Lucas et al., 2019). In addition, though evidence of the

341 ants excavating the agar was observed, we did not assess the number of bacteria ingested by the

342 ants. Perhaps species that showed low mortality herein are species that ingested few or no

343 bacteria, and species that showed high mortality ingested more bacteria. Further experiments that

344 directly assess the health impacts of orally ingesting these non-ant associated bacteria would

345 likely lead to interesting insights on ant immune and antimicrobial responses.

$346 \quad$ Our results hint at an association between ants' use of surface antimicrobials and

347 susceptibility to bacterial exposure. We hypothesize that ants that are susceptible to a broad

348 range of bacteria are more likely to employ antimicrobials (and perhaps less likely to rely on

349 immune responses). This hypothesis could be further tested through the comparison of the

350 antimicrobial responses of a larger number of ant species, perhaps in concert with immunological 351 assays.

352 Although we were unable to demonstrate that exposure altered ants antimicrobial

353 abilities, other studies have shown that ants can immediately change their grooming rates (Reber

354 et al., 2011) and antimicrobial venom usage when threatened by pathogens (Graystock \&

355 Hughes, 2011). Metapleural gland secretions in Acromyrmex octospinosus (Reich, 1793) leaf-

356 cutting ants were found to be significantly greater $12 \mathrm{~h}$ after exposure to some fungal pathogens 
357 (Yek et al., 2012). It is possible that our $6 \mathrm{~h}$ exposure was not long enough for the ants to change

358 metapleural gland expression, or that our exposure treatments were beyond a level that would

359 induce a measurable response. In addition, our preparation of solvent extracts using isopropanol

360 may not have enabled collection of some active compounds which the ants might have been

361 producing in response to our bacterial treatments.

\section{Conclusions}

363

364

365

366

367

368

369

370

371

372

373

374

375

376

377

378

379
Ants, like humans, have evolved in the context of diverse bacterial communities for millions of years. However, unlike humans, "ants" represent $>16,000$ species each with unique life-histories, adaptations, and potential antimicrobial strategies. Like other recent comparative studies in ants (e.g. Bos et al., 2019; Penick et al., 2018), our results show that responses to potentially harmful microbes are varied among ant species. To ants that are susceptible to microbial exposure, threats are not limited to entomopathogenic bacteria. Previous pharmacological studies have demonstrated that some ants produce compounds that inhibit nonant-associated bacteria (e.g. Carvalho et al., 2019; Jouvenaz, Blum \& MacConnell, 1972). These studies may have been revealing that those ants are susceptible to and thus are defending against exposure environmental bacteria. Further exploration of a wide range of both bacteria and ant species is likely to reveal unique and nuanced antimicrobial strategies. Continued research is likely to deepen our understanding of how ant societies maintain health and how we might adopt some of these non-human-society strategies to better improve our own responses to microbial health threats. 
380

381

382

383

384

385

386

387

388

389

390

391

392

393

394

395

396

397

398

399

400

401

\section{Acknowledgements}

Funding for this study was provided by a Triangle Center for Evolutionary Medicine (TriCEM) grant awarded to Adrian Smith. We thank Clint Penick and Stephanie Mathews for their guidance on our methods and analysis.

\section{References}

Baird R, Woolfolk S, Watson CE. 2007. Survey of bacterial and fungal associates of Black/Hybrid Imported Fire Ants from mounds in Mississippi. Southeastern Naturalist 6: 615-32. DOI: 10.1656/1528-7092(2007)6[615:sobafa]2.0.co;2.

Blum MS, Walker JR, Callahan PS, Novak AF. 1958. Chemical, insecticidal, and antibiotic properties of fire ant venom. Science 128: 306-307. DOI: 10.1126/science.128.3319.306-a

Bos N, Kankaanpää-Kukkonen V, Freitak D, Stucki D, Sundström L. 2019. Comparison of twelve ant species and their susceptibility to fungal infection. Insects 10: 271. DOI: 10.3390/insects10090271.

Braun K, Stürzel M, Christina B, Johannes K, Ute K, Lindén M. 2018. Comparison of different cytotoxicity assays for in vitro evaluation of mesoporous silica nanoparticles. Toxicology in Vitro 52: 214-221.

Calvo B, Santafe G. 2016. Scmamp: Statistical comparison of multiple algorithms in multiple problems." The R Journal 8: 248-256.

Carvalho DB, Gonçalves E, Fox P, Gama dos Santos D, Sampaio de Sousa J, Freire DMG, Nogueira FCS, Domont GB, Araujo de Castilho LV, Alcântara Machado E. 2019. Fire ant venom alkaloids inhibit biofilm formation. Toxins 11: 420. DOI: 10.3390/toxins11070420. 
402 Cremer S, Armitage SAO, Schmid-Hempel P. 2007. Social Immunity. Current Biology 17: 693403 702. DOI: $10.1016 /$ j.cub.2007.06.008.

404 Delgado-Baquerizo M, Eldridge DJ, Hamonts K, Singh BK. 2019. Ant colonies promote the 405 diversity of soil microbial communities.” ISME Journal 13: 1114-18. DOI:

406 10.1038/s41396-018-0335-2.

407 García S, Fernández A, Luengo J, Herrera F. 2010. Advanced nonparametric tests for multiple 408 comparisons in the design of experiments in computational intelligence and data mining: experimental analysis of power. Information Sciences 180: 2044-64. DOI:

410 10.1016/j.ins.2009.12.010.

411

Graystock P, Hughes WOH. 2011. Disease resistance in a weaver ant, Polyrhachis dives, and the role of antibiotic-producing glands. Behavioral Ecology and Sociobiology 65: 2319-27. DOI: $10.1007 / \mathrm{s} 00265-011-1242-y$.

Hoggard SJ, Wilson PD, Beattie AJ, Stow AJ. 2011. Social complexity and nesting habits are factors in the evolution of antimicrobial defenses in wasps. PLoS ONE 6: e21763. DOI: 10.1371/journal.pone.0021763.

Hoggard SJ, Wilson PD, Beattie AJ, Stow AJ. 2013. The effectiveness of antimicrobial defenses declines with increasing group size and genetic similarity. Annals of the Entomological Society of America 106: 53-58. DOI: 10.1603/AN11187.

Hughes WOH, Eilenberg L, Boomsma JJ. 2002. Trade-offs in group living: transmission and disease resistance in Leaf-cutting ants. Proceedings of the Royal Society B: Biological Sciences 269: 1811-19. DOI: 10.1098/rspb.2002.2113.

Ishak HD, Plowes R, Sen R, Kellner K, Meyer E, Estrada DA, Dowd SE, Mueller UG. 2011. Bacterial diversity in Solenopsis invicta and Solenopsis geminata ant colonies characterized 
425

426

427

428

429

430

431

432

433

434

435

436

437

438

439

440

441

442

443

444

445

by $16 \mathrm{~S}$ amplicon 454 pyrosequencing. Microbial Ecology 61: 821-31. DOI:

$$
10.1007 / \mathrm{s} 00248-010-9793-4 .
$$

Jouvenaz DP, Blum MS, MacConnell JG. 1972. Antibacterial activity of venom alkaloids from the Imported Fire Ant, Solenopsis invicta Buren. Antimicrobial Agents and Chemotherapy 2: 291-93. DOI: 10.1128/AAC.2.4.291.

Kautz S, Rubin BER, Moreau CS. 2013. Bacterial infections across the ants: Frequency and prevalence of Wolbachia, Spiroplasma, and Asaia. Psyche 2013: 936341. DOI:

$10.1155 / 2013 / 936341$

Kay AD, Bruning AJ, van Alst A, Abrahamson TT, Hughes WOH, Kaspari M. 2014. A carbohydrate-rich diet increases social immunity in ants. Proceedings of the Royal Society

B: Biological Sciences 281: 20132374. DOI: 10.1098/rspb.2013.2374.

Konrad M, Pull CD, Metzler S, Seif K, Naderlinger E, Grasse AV, Cremer S. 2018. Ants avoid superinfections by performing risk-adjusted sanitary care. Proceedings of the National Academy of Sciences 115: 2782-87. DOI: 10.1073/pnas.1713501115.

Konrad M, Vyleta ML, Theis FJ, Stock M, Tragust S, Klatt M, Drescher V, Marr C, Ugelvig LV, Cremer S. 2012. Social transfer of pathogenic fungus promotes active immunization in ant colonies. PloS Biology 10: e1001300. DOI: 10.1371/journal.pbio.1001300.

Levy SB. 1992. From tragedy the antibiotic age is born. In: The Antibiotic Paradox. Boston, MA: Springer.

Lofgren CS, Banks WA, Glancey BM. 1975. Biology and control of Imported Fire Ants. Annual Review of Entomology 20: 1-30. DOI: 10.1146/annurev.en.20.010175.000245. 
446 Lucas JM, Madden AA, Penick CA, Epps MJ, Marting PR, Stevens JL, Fergus DJ, Dunn RR, 447 Meineke EK. 2019. Azteca ants maintain unique microbiomes across functionally distinct 448 nest chambers. Proceedings of the Royal Society B: Biological Sciences 286: 20191026.

449 MacGowen J. 2014. Ants (Formicidae) of the Southeastern United States. Available at $450 \quad$ https://mississippientomologicalmuseum.org.msstate.edu/Researchtaxapages/Formicidaepa 451 ges/Identification.Keys.htm (accessed 01 August 2020).

452 Mackintosh JA, Trimble JE, Beattie AJ, Veal DA, Jones MK, Karuso PH. 1995. Antimicrobial 453 mode of action of secretions from the metapleural gland of Myrmecia gulosa (Australian 454 Bull Ant). Canadian Journal of Microbiology 41: 136-44. DOI: 10.1139/m95-018.

455 Meunier J. 2015. Social immunity and the evolution of group living in Insects. Philosophical 456 Transactions of the Royal Society B: Biological Sciences 370: 19-21. DOI:

457 10.1098/rstb.2014.0102.

458 Penick CA, Halawani O, Pearson B, Mathews S, López-Uribe M.M., Dunn RR, Smith AA. 2018. 459 External immunity in ant societies: sociality and colony size do not predict investment in $460 \quad$ antimicrobials. Royal Society Open Science 5: 171332. DOI: 10.1098/rsos.171332.

461 Pull CD, Ugelvig LV, Wiesenhofer F, Grasse AV, Tragust S, Schmitt T, Brown MJF, 462 Cremer S. 2018. Destructive disinfection of infected brood prevents systemic disease 463 spread in ant colonies. eLife 7: e32073. DOI: 10.7554/eLife.32073.

464 R Core Team. 2017. R: A language and environment for statistical computing. R Foundation. 465 (Vienna, Austria): URL https://www.R-project.org/.

466 Ramalho MO, Bueno OC, Moreau CS. 2017. Microbial composition of Spiny ants 467 (Hymenoptera: Formicidae: Polyrhachis) across their geographic range. BMC Evolutionary 468 Biology 17: 96. DOI: 10.1186/s12862-017-0945-8. 
469 Reber A, Purcell J, Buechel SD, Buri P, Chapuisat M. 2011. The expression and impact of 470 antifungal grooming in ants. Journal of Evolutionary Biology 24: 954-64. DOI:

471 10.1111/j.1420-9101.2011.02230.x.

472 Schlüns H, Crozier RH. 2009. Molecular and chemical immune defenses in ants (Hymenoptera: $473 \quad$ Formicidae). Myrmecological News 12: 237-49.

474 Schmid-Hempel P. 1998. Parasites in Social Insects. Princeton, New Jersey: Princeton $475 \quad$ University Press.

476 Sengupta S, Chattopadhyay MK, Grossart HP. 2013. The multifaceted roles of antibiotics and 477 antibiotic resistance in nature. Frontiers in Microbiology 4: 1-13. DOI:

478 10.3389/fmicb.2013.00047.

479

480

481

482

483

484

485

486

487 488 Evidence for the group facilitation of disease resistance. Proceedings of the National 489 Academy of Sciences 99: 6838-42. DOI: 10.1073/pnas.102176599.

Stow A, Briscoe D, Gillings M, Holley M, Smith S, Leys R, Silberbauer T, Turnbull C, Beattie A. 2007. Antimicrobial defenses increase with sociality in bees. Biology Letters 3: 422-24. DOI: $10.1098 / \mathrm{rsbl} .2007 .0178$.

Stucki D, Freitak D, Bos N, Sundström L. 2019. Stress responses upon starvation and exposure to bacteria in the ant Formica exsecta. PeerJ 7: e6428. DOI: 10.7717/peerj.6428.

Tragust S, Metteregger B, Barone V, Konrad M, Ugelvig LV, Cremer S. 2013. Ants disinfect fungus-exposed brood by oral uptake and spread of their poison. Current Biology 23: 1-7, DOI: 10.1016/j.cub.2012.11.034

Traniello, JFA, Rosengaus RB, Savoie K. 2002. The development of immunity in a social insect: 
490 Turnbull C, Hoggard S, Gillings M, Palmer C, Stow A, Beattie D, Briscoe D, Smith S, Wilson P, 491 Beattie A. 2011. Antimicrobial strength increases with group size: Implications for social 492 evolution. Biology Letters 7: 249-52. DOI: 10.1098/rsbl.2010.0719.

493 Wenseleers T, Ito F, Van Borm S, Huybrechts R, Volckaert F, Billen J. 1998. Widespread 494 occurrence of the micro-organism Wolbachia in ants. Proceedings of the Royal Society B: 495 Biological Sciences 265: 1447-52. DOI: 10.1098/rspb.1998.0456.

496 Wickham H, Francois R, Henry L, Müller K. 2018. Dplyr: A grammar of data manipulation. R 497 package. Available at https://CRAN.R-project.org/package=dplyr (accessed 01 May 2020). 498 Yek SH, Mueller UG. 2011. The metapleural gland of ants. Biological Reviews 86: 774-91. 499 DOI: $10.1111 /$ j.1469-185X.2010.00170.x.

500 Yek SH, Nash DR, Jensen AB, Boomsma JJ. 2012. Regulation and specificity of antifungal 501 metapleural gland secretion in leaf-cutting ants. Proceedings of the Royal Society B:

502 Biological Sciences 279: 4215-4222. DOI: 10.1098/rspb.2012.1458. 
Figure 1

Mortality is shown for data collected at $24 \mathrm{~h}(\mathrm{~A})$ and $48 \mathrm{~h}(\mathrm{~B})$ when ants were exposed to $S$. epidermidis $(\mathrm{S})$ or E. coli $(\mathrm{E})$ after adjusting treatment values to control value.

15 colonies were tested for each species. Asterisks indicate statistically significant difference in mortality, relative to the control according to Friedman's rank sum test and Finner posthoc test. Box plot line represents median values, whiskers represent 1st and 3rd quartile, data points represent ant colonies, outliers are data outside of 1.5 IQR.
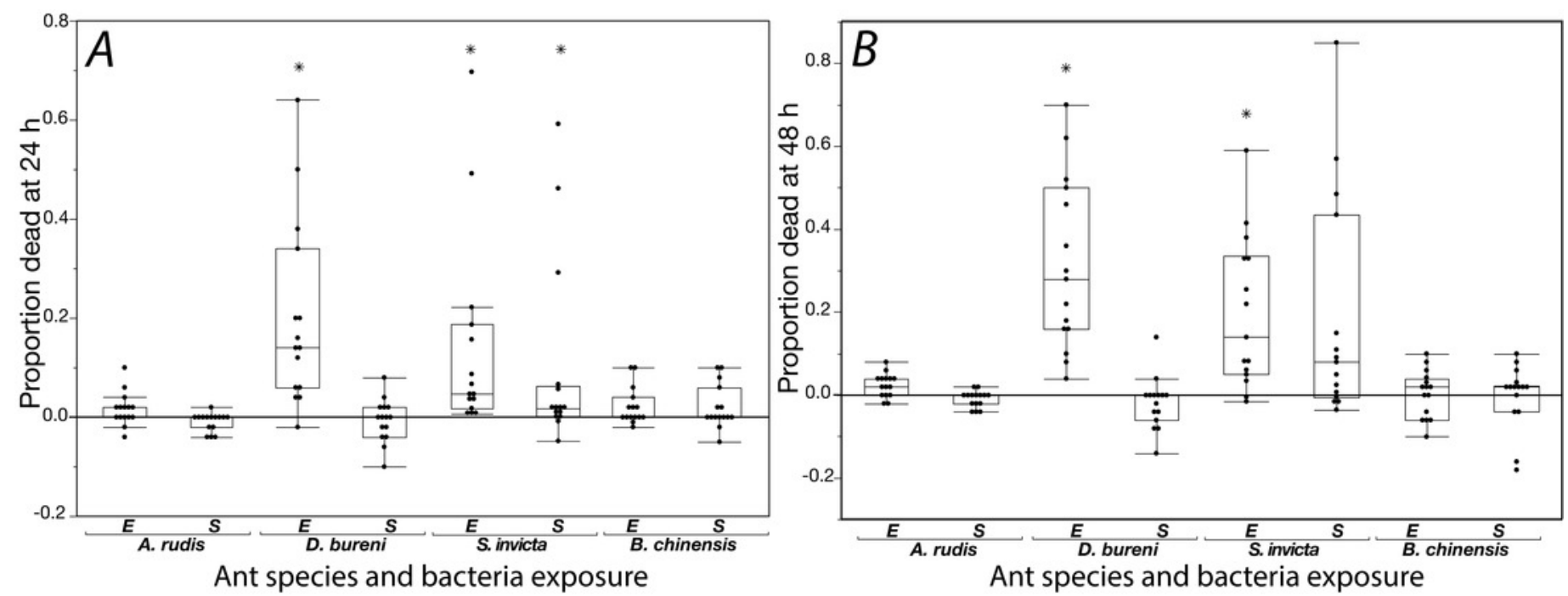
Figure 2

Extracts from S. invicta effectively inhibited bacterial challenge similarly with or without treatment exposures.

Bacterial inhibition of isopropanol extracts from ants when exposed to either E. coli (A) or S. epidermidis $(B)$ or control agar $(A \& B)$. Values are percent inhibition of extracts compared to growth controls. There are no statistically significant differences between control and treatment groups. Box plot line represents median values, whiskers represent 1st and 3rd quartile, data points represent ant colonies, outliers are data outside of 1.5 IQR.
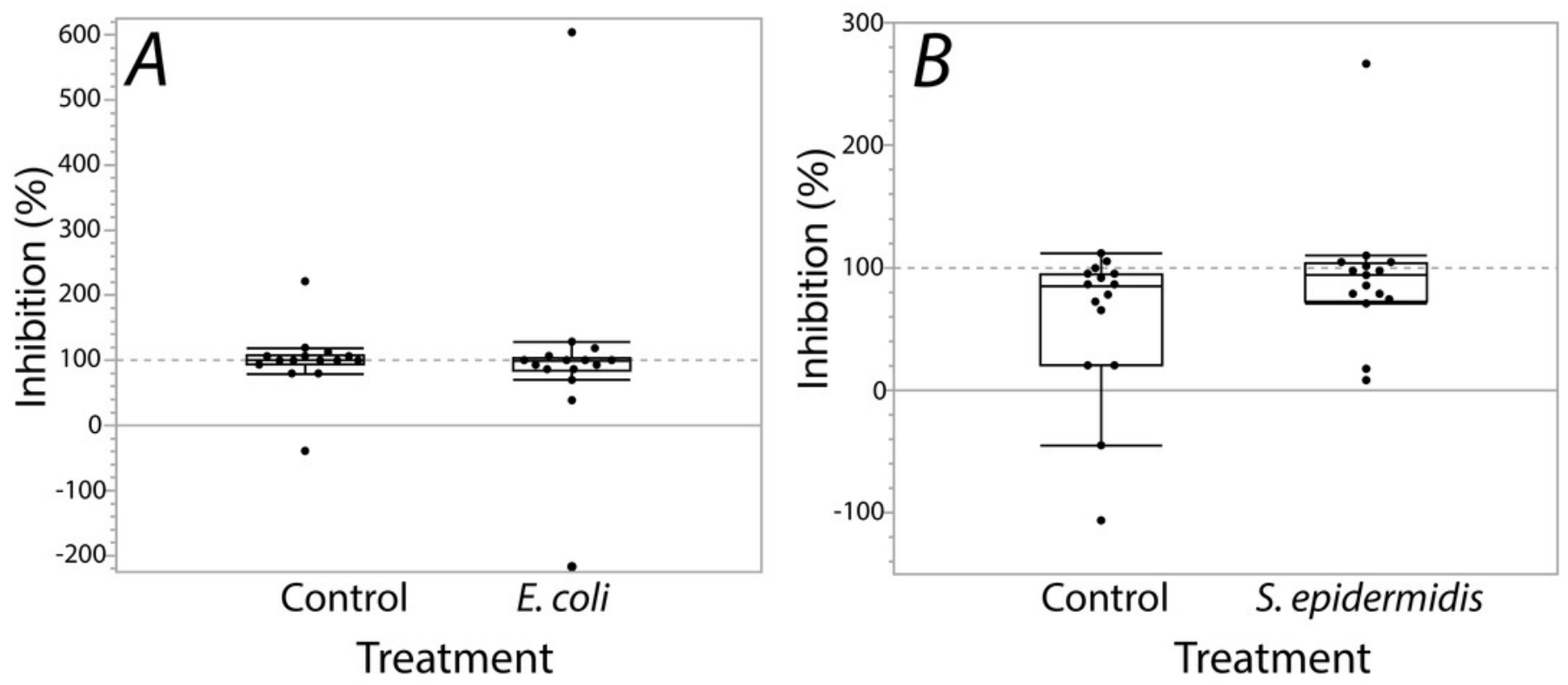
Figure 3

Extracts from $B$. chinensis showed similar bacterial inhibition ability with or without treatment exposures.

B. chinensis inhibition potential for control and treatment exposures for isopropanol extracts when exposed to E. coli (A) or S. epidermidis (B). Values are percent inhibition of extracts compared to growth controls. There are no statistically significant differences between control and treatment groups. Maximum and minimum growth controls visualized at $100 \%$ and $0 \%$, respectfully.
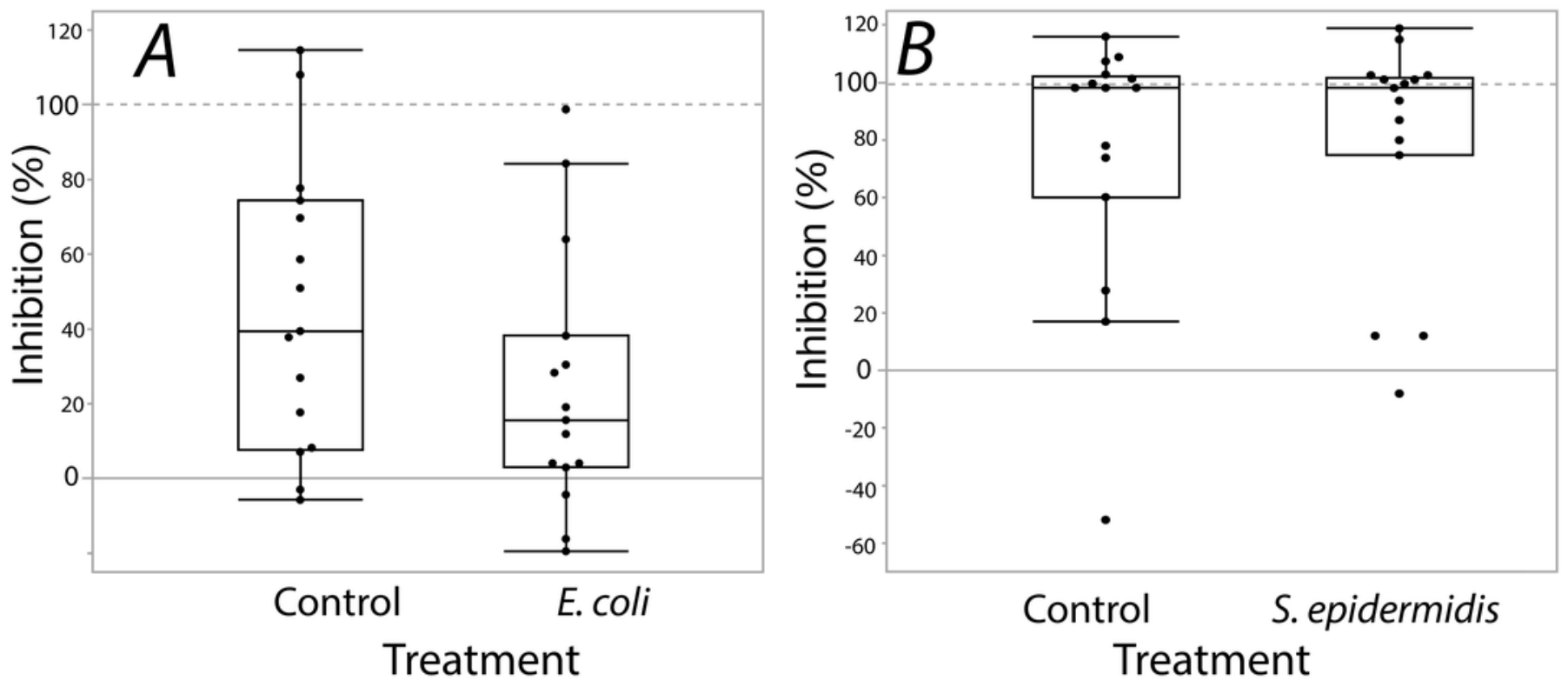


\section{Table 1 (on next page)}

Statistical comparisons for experiment 1, corresponding with Figure 1.

Bold entries correspond with statistical significance in post-hoc analyses. 
1 Table 1: Statistical comparisons for experiment 1, corresponding with Figure 1. Bold entries correspond with statistical 2 significance in post-hoc analyses.

\begin{tabular}{|c|c|c|c|c|c|c|}
\hline \multirow{2}{*}{$\begin{array}{l}\text { Species } \\
24 \text { h exposure }\end{array}$} & \multirow[b]{2}{*}{$\begin{array}{c}\text { Friedman's } \\
\text { chi- } \\
\text { squared }\end{array}$} & \multirow[b]{2}{*}{ df } & \multirow[b]{2}{*}{$\mathrm{p}$ value } & \multicolumn{3}{|c|}{ Post-hoc comparisons: Finner p value; Cohen's $d$ effect size } \\
\hline & & & & $\begin{array}{l}\text { E. coli vs. } \\
\text { control }\end{array}$ & $\begin{array}{l}\text { S. epidermidis vs. } \\
\text { control }\end{array}$ & $\begin{array}{l}\text { S. epidermidis vs. } \\
\text { E. coli }\end{array}$ \\
\hline S. invicta & 8.93 & 2 & $\mathrm{p}=0.011$ & $0.0001 ; 0.74$ & $0.0026 ; 0.68$ & $0.41 ; 0.18$ \\
\hline D. bureni & 23.33 & 2 & $\mathrm{p}<0.0001$ & $0.0005 ; 1.27$ & $0.78 ; 0.16$ & $0.0003 ; 1.32$ \\
\hline A. rudis & 6.63 & 2 & $\mathrm{p}=0.036$ & $0.23 ; 0.56$ & $0.37 ; 0.53$ & $0.062 ; 0.92$ \\
\hline B. chinensis & 2.23 & 2 & $\mathrm{p}=0.33$ & & & \\
\hline \multicolumn{7}{|l|}{$48 \mathrm{~h}$ exposure } \\
\hline S. invicta & 16.3 & 2 & $\mathrm{p}=0.022$ & $0.021 ; 0.8$ & $0.087 ; 0.69$ & $0.42 ; 0.04$ \\
\hline D. bureni & 19.733 & 2 & $\mathrm{p}<0.0001$ & $0.0005 ; 5.74$ & $0.42 ; 0.34$ & $0.00003 ; 5.95$ \\
\hline A. rudis & 10.03 & 2 & $\mathrm{p}=0.0066$ & $0.07 ; 0.77$ & $0.37 ; 0.38$ & $0.011 ; 1.11$ \\
\hline B. chinensis & 2.84 & 2 & $\mathrm{p}=0.24$ & & & \\
\hline
\end{tabular}

